\title{
SUB-ACUTE RUMINAL ACIDOSIS IN DAIRY COWS: ITS CAUSES, CONSEQUENCES AND PREVENTIVE MEASURES
}

\author{
Emran HOSSAIN
}

Professor and Head, Department of Animal Science and Nutrition, Faculty of Veterinary Medicine, Chattogram Veterinary and Animal Sciences University, Zakir Hossain Road, Khulshi, Chattogram-4225, Bangladesh

Email: emran@cvasu.ac.bd; (i) ORCiD: 0000-0002-1750-7284

supporting Information

\begin{abstract}
Current feeding programs for cattle prescribe concentrate rich diets to meet their ever increasing demands for high levels of milk production. These diets, however, can impair rumen health and thus cattle production, milk yield and welfare. High energy diets are rapidly fermented in the rumen because they are high in fermentable starch, low in NDF and contain finely chopped digestible forages. Feeding rapidly fermentable diet to the cows predominantly adapted to digest and metabolize forage based total mixed ration (TMR) substantially increases short term milk yield, but the risk of sub- acute ruminal acidosis (SARA) increases. Additionally, too high concentrate to forage ratio, too fast a switch from high forage to high concentrate, diet composed of highly fermented feeds, improperly mixed TMR and mycotoxins in feed also increases the incidence of SARA in dairy herds. SARA causes depressed feed intake, cycling feeding, reduced cud chewing, poor fibre digestion, rumenitis, mastitis, metritis, dehydration, diarrhoea, abomasal displacement, pulmonary bacterial emboli, systemic inflammation, liver abscesses, low milk fat, low milk protein, sore hooves, laminitis and low fertility. Therefore, SARA is a major challenge for animal health, productivity, economic efficiency and welfare issue even in well managed dairy herds. Feeding higher amounts of forages, supplying adequate peNDF, processing grains less thoroughly, reducing fermentability of the carbohydrate fraction and adapting rumen to the dietary changes are the key factors to be considered for preventing SARA. Continued research for accurate quantification of peNDF in diet, grain processing, optimization of meal size, dietary cation-anion balance, narrowspectrum rumen modifier, inoculation of lactate utilizing microbes, inhibition of lactate producing microbes and innovation of the unique fermentability characteristics of feed ingredients to promote sufficient buffering and rapid absorption of VFA from rumen will explore new horizon for reducing incidence of SARA in future.
\end{abstract}

Keywords: Acidosis, Cattle, Dairy herd, Rumen, Total mixed ration.

\section{INTRODUCTION}

The sub-acute ruminal acidosis (SARA) is a global threat which causes reduced dry matter intake and digestibility (Coon et al., 2019), change in bacterial density, assorted variety and community structure of the microorganism in the rumen (Plaizier et al., 2017), reduced microbial protein synthesis (de Veth and Kolver, 2001), decreased milk yield (Stone, 1999), reduced milk fat substance (Coon et al., 2019), modified lipid profile of milk (Jing et al., 2018), decreased conception rate (Khalouei et al., 2016), liver abscess (Wiese et al., 2017) and laminitis (Nocek, 1997). SARA has been characterized as a condition portrayed by critical ruminal $\mathrm{pH}$ and increased accumulation of short chain unsaturated fatty acids (SCFA) because of an imbalance between the production of fermentation acids by rumen microorganisms and the retention, absorption and buffering of those acids (Allen et al., 2006). SARA results altered volatile fatty acids, i.e., acidic, propionic and butyric acids towards elevated butyric and propionic acids and increased lactic acids in the rumen in 5-10 mmol/I (Enemark et al., 2002). An edge estimation rumen pH of 5.5 to 5.8 is typically used to characterize SARA (Yang and Beauchemin, 2006) since the vast majority of the cellulolytic microorganisms don't increase below pH 6.0 (Russell and Wilson, 1996). SARA is a result of feeding highly fermentable carbohydrate to the cows adjusted to process and use dominatingly forage based diets (Krause and Oetzel, 2006). However, it might likewise happen in pasture fed dairy cows when digestibility of the field forages are substantially high.

SARA is a typical issue in practically all the dairy herds not just for animal health, profitability and productivity (Plaizier et al., 2008), yet additionally for animal welfare issues (Krause and Oetzel, 2006). It was accounted for that, SARA decreased milk yield by $2.7 \mathrm{~kg} /$ day, milk fat production by $0.3 \%$ and milk protein production by $0.12 \%$ (Stone, 1999). Lameness is another important animal welfare issue in dairy herds and SARA has been perceived as an important hazard factor for laminitis (Nocek, 1997). Lameness is normally the most important purpose behind untimely culling of 
cows in a dairy herd. Furthermore, SARA has an immediate human health concern. Low ruminal and intestinal pH due to SARA expands the hazard for shedding enterohemorrhagic E. coli, for example, 0157:H7 (Russell and Rychlik, 2001). Dairy cows require high energy diets to fulfill their elevated needs for increased levels of milk production. However, high energy diets are quickly fermented in the rumen and magnify the danger of SARA. Accordingly, this is a significant challenge for dairy owners to improve animal health, profitability and financial effectiveness without challenging SARA.

\section{CAUSES OF SARA}

\section{Feeding rapidly fermentable carbohydrate}

Feeding quickly fermentable diets to the cows recently adjusted to digest and utilize forage based diet is the most agreed explanation of SARA in dairy herds. In any case, all in all, too high concentrate to forage proportion, too quick a change from high forage to high concentrate and low peNDF content in diet are generally regular to SARA. SARA is brought about by the accumulation of VFAs and lactic acid in the rumen. As feed is digested in rumen, VFAs are produced, consumed or buffered in rumen. However, $\mathrm{pH}$ in the rumen drops if production of VFAs are quick and ingestion or buffering is low which surpasses the limit of the rumen to keep up harmony and at last a cyclic example of SARA happens. In a normal healthy rumen, lactic acid production normally rises to lactic acid use. In this manner, lactic acid focus is in every case brief and infrequently discernible. Under typical rumen $\mathrm{pH}$, lactate-using microscopic organisms, for example, Megasphaera elsdenii and Selenomonas ruminantium, proceed to multiply and begin processing lactate to change over in different VFAs, which are then effectively protonated and retained (Goad et al., 1998). Most of the lactate produced can be used by these microbes. In any case, because of feeding overabundance fermentable carbohydrate, abundance propionate gathers in the rumen, lower ruminal $\mathrm{pH}$, restrain multiplication of cellulolytic microscopic organisms and favor the development of lactate-producing microorganisms. As lactate delivering microscopic organisms multiply, pH pointedly dips under 6.0 and hinders the development of useful lactate using microbes. The turnover time of lactate using microscopic organisms is much slower than lactate creating microorganisms. Thus, lactate production quickly surpasses lactate use (Russell and Allen, 1984). Lactic acid is around multiple times more grounded than the other rumen acids and makes rumen $\mathrm{pH}$ drop forcefully. As an outcome, there is an imbalance of lactic acid digestion alongside expansion of VFAs coming about in SARA.

\section{Inadequate peNDF in diet}

In ruminant animal, salivary buffer production relies upon length and force of cud chewing. Chewing time is influenced by the substance of coarse fiber in the diet. The measure of genuine coarse fiber is evaluated by estimating the peNDF which has been characterized as the capacity of a feed to invigorate chewing and buffering of salivation in the rumen (Mertens, 1997). The fundamental factor that decides dietary peNDF content is the particle size appropriation and NDF substance of the diet, however different elements, for example, particle delicacy can likewise assume a purpose. Mature forages of appropriate chop length are a decent source of peNDF in contrast with cereal grains and crop residues (Krause and Combs, 2003). Besides invigorate saliva production, they add to rumen buffering through their inborn buffering component. Accordingly, as the measure of peNDF reduces in diet, chewing time just as salivary buffer production likewise reduces proportionately and causes frequency of SARA (Yang and Beauchemin, 2006).

\section{Insufficient rumen buffering}

Ruminant animals have restricted framework for buffering natural acids produced from ruminal fermentation of carbohydrates (Oetzel, 2015). In saliva the fact that, the genuine impact of buffering on ruminal pH is substantial in a forage based diet, in any case, it is moderately little on diets enhanced with quickly fermentable carbohydrate. There are two unique sorts of buffering i.e., exogenous and endogenous buffering. Dietary buffering is the exogenous buffering framework which decides real dietary cation-anion contrast (DCAD). Thusly, diets high in $\mathrm{Na}$ and $\mathrm{K}$ comparative with $\mathrm{Cl}$ and $\mathrm{S}$ have higher DCAD edge to kill higher ruminal $\mathrm{pH}$ for keeping up normal health and milk yield (Hu and Murphy, 2007). Forages normally have higher DCAD, however, concentrates have extremely low DCAD potential and consequently, diets wealthy in concentrate are consistently helpless to SARA (Oetzel, 2015). Endogenous buffers produced in vivo by cow are discharged into the rumen through the salivation. Coarse, stringy feeds contain progressively viable fiber and invigorate more salivation production during eating than do finely ground TMR and concentrate work. Therefore, as the degrees of quickly fermentable carbohydrate increments in diet, cows become increasingly inclined to SARA.

\section{Inadequate adaptation}

A fast increment of highly fermentable concentrate in diet of the cows adjusted to process forage based diets expands the hazard for SARA since rumen microorganisms and the rumen wall can't adjust proportionately to the abrupt dietary changes. Deficient concentrate feeding during dry off period may likewise expand the danger of SARA due to damage of the ruminal papillae to build as needs be and disruption of rumen microbial population to adjust to unexpected high concentrate diets took care of later on (Dirksen et al., 1984). The short chain unsaturated fatty acids (SCFA) are generally viewed as luminal development factors and expanding their production modifies expansion of alimentary tract in ruminants. In light of gradually elevated SCFA fixation got from progressively expanding quickly 
fermentable diet, the ruminal epithelium endeavor to adjust slowly by expanding epithelial expansion, cell capacity and tissue penetrability (Penner et al., 2011). In any case, out of nowhere elevated quickly fermentable carbohydrate of the diet suddenly changes the rate of production of SCFA, for the most part acetic acid, propionate and butyrate (Plaizier et al., 2008). The rumen microorganisms and the rumen walls can't adjust proportionately to these abrupt dietary changes and at last SARA happens.

\section{Sorting of TMR particle}

Specifically sorting relatively progressively tasteful medium size forage particles even from a homogenous TMR is a typical inclination among dairy cows which lead them to expend a real imbalanced fiber consumption (Leonardi and Armentano, 2003) than determined in TMR. Ongoing examination shows that, lactating dairy cows exhibit higher degrees of sorting for medium size forage and concentrate particle against longer forage and smaller grain particles when taken care of a low forage diet. This kind of sorting conduct altogether reduces intake of sufficient peNDF from the TMR which continuously contributes to the occurrence of SARA in dairy herds.

\section{Other causes}

Dry matter intake in primiparous cows is lower than the older cows. In this way, apparently, the primiparous cows are at lower danger of SARA than the older cows. Nonetheless, consequences of a few examinations demonstrate that, primiparous cows are at higher hazard for SARA (Krause and Oetzel, 2006). Primiparous cows may require time to become acclimated to learn control their feed consumption when acquainted with a high-energy diet just because in the wake of calving. They may likewise endure experiencing issues accessing feed bunks when older cows are available in a similar line (Oetzel, 2015).

\section{CONSEQUENCES OF SARA}

\section{Milk fat depression}

The relationship between SARA and milk fat depression is not consistent and it is really difficult to determine if a herd has a low milk fat test or not (Oetzel, 2015). Milk fat percentage generally depends on feed, breed, season and days in milk (Palmquist et al., 1993). According to the most popular substrate supply limitation theories, milk fat synthesis is limited by poor acetate supply since acetate is the principal precursor for biosynthesis of milk fat (Thomas and Martin, 1988). However, the reduced ratio of acetate to propionate with highly fermentable diet is predominantly due to increased ruminal production of propionate. Additionally, ruminal infusion of acetate to cows suffering from SARA has only a marginal or no impact on milk fat synthesis (Bauman and Griinari, 2001). Therefore, substrate limitation theory appears almost immaterial (Bauman et al., 2011).

According to recent research, excessive intake of unsaturated fat is the most predictable reason of milk fat depression in dairy cows (Vargas-Bello-Pérez and Garnsworthy, 2013). Ruminant's diets are mostly consisting of unsaturated fatty acids that are extensively bio-hydrogenated in rumen. Conjugated linoleic acids are the unique intermediates in the biohydrogenation process and represent a mixture of positional and geometric isomers of octadecadienoic acid with variable conjugated double bonds (e.g., 7-9, 8-10, 9-11, 10-12) and can exist in different configurations (cis-trans, trans-cis, cis-cis, or trans-trans (Bauman et al., 1999). However, the major isomer of CLA in milk fat is cis-9, trans-11 which represents 80 to $90 \%$ of the total CLA (Parodi, 1977). Recent studies have demonstrated that, the cis-9, trans-11 isomers are produced in normal proportion only under healthy ruminal condition and they can prevent cancer and tumor (Ip et al., 1999).

Under certain dietary conditions, such as high-concentrate, low-fiber diets, lower acetate to propionate molar ratio and decreased rumen $\mathrm{pH}$, typical pathways of rumen biohydrogenation are altered to produce some unique fatty acid intermediates so that the concentration of the trans-10, cis-12 isomer increases in milk fat (Griinari and Bauman, 1999). These fatty acids are absorbed at the small intestine, taken up by the mammary gland and ultimately inhibit milk fat synthesis (Oetzel, 2015). Studies with pure isomers have ascertained that, the trans-10, cis-12 CLA is a potent inhibitor of milk fat synthesis. The inhibition mechanism involves a coordinated reduction in mRNA abundance decreasing the $\Delta 9$ desaturase activity in the biochemical pathways of fat synthesis (Bauman et al., 2011).

In a series of studies, administration of CLA supplements to lactating dairy cows exhibited a dramatic reduction in the content and yield of milk fat. In a study, abomasal infusion of $60 \%$ CLA resulted greater than $50 \%$ reduction in milk fat (Giesy et al., 1999). In another study, abomasal infusion of the pure isomers of trans-10, cis-12 CLA reduced milk fat percentage and yield by 42 and 44\%, respectively (Bauman et al., 1999). However, similar amount of cis-9, trans-11 CLA infusion had no effect on milk fat depression (Baumgard et al., 2000). Additionally, SARA may increase trans fatty acid uptake of host animals, perhaps by inhibiting certain bacteria which are responsible for complete biohydrogenation of fatty acids in the rumen (Plaizier et al., 2008).

\section{Lameness}

When the microvasculature of the corium is affected by vasoactive substances, then vascular destruction is inevitable. When blood is not returned to circulation by the musculature of the vascular system, then seepage and 
hemorrhage result. Laminitis is associated with inflammation of local corium which involves vascular breakdown, hemorrhage and exudation of the serum from capillary beds. As the horn tissue of the sole grows, the hemorrhage moves to the external surface and ultimately, external tissue of the sole exhibits internal hemorrhage which is the visual symptom of laminitis (Nocek, 1997).

The progression from SARA to laminitis is associated with several systemic phenomena. However, the most common strategic and critical apex in the entire process is the reduction of ruminal $\mathrm{pH}$ which results metabolic and digestive disorders, localized trauma and vascular destruction. Destruction of the hemodynamics of the peripheral microvasculature due to SARA has been identified as a major etiological factor associated with development of laminitis (Nocek, 1997). Various theories have been developed to explain the pathogenesis of laminitis. Elevation of vasoactive substances especially histamine and endotoxins have been reported during occurrence of laminitis (Nocek, 1997). Elevated serum histamine concentration was related with corium tissue breakdown and elevated endotoxins were related with bacteriolysis due to decline of ruminal pH (Nocek, 1997)..

Histamine has long been identified as a potent vasodilator and arterial constrictor (Chavance, 1946). Brent (1976) indicated that, histamine increases capillary permeability and arteriolar dilatation. Windholz et al. (1976) identified histamine as a potent vasodilator and Chavance (1946) identified histamine as a potent arterial constrictor. If histamine is an arterial constrictor and vassal dilator, blood pressure and flow would increase to the capillary beds (Nocek, 1997). As a result, pooling, vessel rupture, serum seepage and hemorrhage will occur. However, if the reverse is the case, then pooling would also occur because of constriction of veins rather than arteries. In any event, the impedance of blood flow and pressure build up within capillaries will force fluid through the vessels into the interstitial tissue spaces setting up ischemia (Nocek, 1997).

In equine research, endotoxin administration resulted in vasoconstriction and arteriovenous shunting, which lead to poor perfusion of the digit and laminitis (Hunt, 1990). Boosman et al. (1991) administered endotoxin to cattle and created histopathologic lesions in the digit consistent with laminitis.

\section{Liver abscess}

SARA is associated with a chain of events that liberate Fusiformis necrophorus, Fusobacterium necrophorum, gramnegative, obligate anaerobic bacterium which is the primary etiologic agent of liver abscess (Oetzel, 2015). Low ruminal $\mathrm{pH}$ damages the surface of the rumen wall and causes ulceration of the epithelium. Once the ruminal epithelium is damaged, bacteria transported to the liver through portal circulation, causing liver abscesses. Infection in the liver originates from a necrobacillary rumenitis. Two biovars have been identified. Biovar A (F necrophorum necrophorum) the more virulent and predominant biovar in the rumen microflora isolated in pure culture from liver abscess. Biovar $B$ ( $F$ necrophorum funduliforme) is isolated from microabscesses in rumen wall and less commonly isolated from liver abscesses. Arcanobacterium pyogenes, streptococci, staphylococci and Bacteroides spp are most frequently recovered from mixed cultures. $F$ necrophorum, alone or with other bacteria, colonizes through the area of superficial necrosis produced in rumen under condition of SARA. Leukotoxin facilitate resistance to phagocytosis. Bacterial emboli from the lesions invade the hepatic portal venous system and transported to the liver, where they establish infectious foci of necrobacillosis which eventually develop liver abscesses (Krause and Oetzel, 2006).

\section{Reduced feed intake}

Reduced dry matter intake is supposed to be a reliable clinical sign and a few examinations have indicated a depressed hunger (Shinozaki, 1959), lower rumen motility (Ash, 1959), decreased fiber digestibility (Hoover, 1986) and reduced feed consumption (Fairfield et al., 2007) due to SARA. The depression in feed intake may have been because of elevated production of unstable unsaturated fats, particularly propionate and changes in the osmolarity in the rumen (Allen, 2000). It was accounted for that, grain induced SARA decreased in situ fiber digestibility in the rumen because of increased rumen acidity (Krajcarski-Hunt et al., 2002) and increased VFA production in rumen (Khafipoor et al., 2007). In any case, SARA prompted by feeding horse feed pellets came about no adjustment in DMI. The dissimilarity between the impacts of grain initiated SARA and pellet induced proposes that there may have different variables answerable for intake depression. A few examinations have demonstrated that grain-instigated SARA causes an expansion in acute stage proteins in blood, which is a marker of aggravation (Gozho et al., 2007). It has been indicated that irritation of different organs of the cow decreases feed intake (Andersen et al., 2003). Subsequently, the irritation coming about because of grain actuated SARA could add to the feed intake depression. This supposition that is fortified by the perception that enlistment of SARA by supplanting hay feed with hay pellets did not bring about aggravation and furthermore did not bring about feed intake depression (Khafipoor et al., 2007).

\section{Cyclic feeding}

Cyclic feeding design has been portrayed as the most reliable manifestation of SARA (Britton and Stock, 1987). Normally, the image is one of cyclic feed intake as the cow eats its proportion and subsequently declines further feed because of an uncommon fall in rumen $\mathrm{pH}$ coming about increased osmolality of the rumen liquid. Upon reestablishment of normal rumen conditions, appetite is often regained (Fulton et al., 1979). The course proceeds and subsequently, cyclic feeding creates. 


\section{Feed sorting}

It has been accounted for that, whenever given chance, ruminants select diet trying to reduce the impacts of low ruminal $\mathrm{pH}$ to help keep up a sound ruminal condition. It has additionally been accounted for that, lactating dairy cows experiencing SARA favored long forage particles (Yang and Beauchemin, 2006) perhaps in endeavor to address their issue for peNDF. It was detailed that, feed sorting was influenced by the extents of purposefully induced acidosis of the cows. Both high and safe cows change their sorting conduct in light of acidosis difficulties and acidosis was related with elevated sorting for the longer particles against the shorter one.

\section{Poor feed efficiency}

Low ruminal pH disrupts ruminal mucosa causing ulceration of the epithelium (Krause and Oetzel, 2006). Moreover, over the top keratinization of the ruminal epithelium happened as an outcome of SARA results decreased absorptive limit (Krehbiel et al., 1995), reduced profitability and increased feed costs because of poor digestibility and lower feed effectiveness. It was accounted for that, ruminal NDF digestion declined from $52 \%$ for cows with a mean ruminal $\mathrm{pH}$ of 6.4 to $44 \%$ for cows encountering rehashed scene of SARA with a mean ruminal pH of 5.8 .

\section{Impaired microbial protein synthesis}

SARA reduces digestibility of organic matter subsequently brings down the productivity of microbial protein amalgamation in rumen which at last declines the yield of microbial protein except if increasingly fermentable carbohydrate is provided. The reduced microbial protein blend expands the requirement for increasingly supplemental feed protein in the diet of the host animal (Beauchemin et al. 2003).

\section{Abomasal displacement}

SARA has frequently been considered as a hazard factor for abomasal displacement (Shaver, 1997; Enemark, 2008). Although a causal relationship has not been demonstrated, in any case, increased in reverse and forward progression of ruminal gasses among stomach and the front stomachs are accepted to bring about abomasal atony and dilatation and subsequent removal (Sarashina et al., 1990). The hypothesis is upheld by the finding that a low fiber content in the feed proportion is the most important single factor in the event of abomasal dislodging (Shaver, 1997) and that the foundation of a practical fiber tangle in the drifting layer is accepted to be of significance in the more continuous production and ingestion of VFA in the forestomachs (Enemark, 2008). The event of abomasal ulcers has been connected to management and feeding of acidic diets comprising of concentrates and silage.

\section{Rumenitis}

Rumenitis is one of the most incessant spin-offs of rumen acidosis. The pathogenesis is not plainly seen, however, an increased production of VFA especially butyrate and propionate just as a brief ascent in ruminal lactate focus and variances in the osmolality of the rumen liquid may confuse advancement of rumenitis (Krehbiel et al., 1995). Parakeratosis is an outcome of increased lactate production which results mucosal sore. Mucosal injuries in rumenitis encourage passageway of Fusobacterium necrophorum and once in a while Acanobacterium pyogenes and help their subsequent colonization in the submucosa. Embolic spread to the liver makes development of hepatic boil with metastasis the aspiratory course by means of back vena cava causing burst of minor pneumonic corridors into the bronchi. Clinically these scenes may prompt epistaxis and haemoptysis portrayed by bleeding, frothing expectorate around the gag and nostrils showing indications of lethal rumenitis (Nordlund et al., 1995; Enemark, 2008).

\section{Bloat}

Swell is of specific issue in dairy herds kept up on high concentrate diet. The genuine connections have not yet been built up however the mix of decreased rumen motility brought about by a low fiber ration and subsequently a low rumen $\mathrm{pH}$, extreme production of mucopolysaccharides and arrival of obscure macromolecules from rumen microorganisms because of bacterial crumbling should bring about the development of a steady froth upsetting eructation of gases from rumen (Cheng et al., 1998). In any case, rumen balance because of low rumen pH may likewise contribute accumulation of free gases coming about swell.

\section{Diarrhoea}

The diarrhoea has been related with SARA in dairy herds (Oetzel, 2015). It was accounted for that, cows expending low fiber diets and experiencing SARA had more fluid excrement than cows on high forage diet. Excrement from cows with SARA seemed more brilliant and more yellowish than the dung of cows without SARA (Kleen et al., 2003). Frothy dung and loose bowels propose poor ruminal and broad hindgut fermentation related with SARA. Fermentation in the hindgut produces VFA and carbon dioxide. These VFAs can be consumed, yet gas is gotten away in hindgut and produces rises in dung giving them the 'frothy' appearance. Hindgut fermentation likewise brings about increased acidity of the hindgut substance. The increased acidity prompts sloughing of the epithelial cells in the digestive organ discharged with faces. As hindgut gets serious acidic, more water from epithelial cells come to neutralize it. As a result, poor consistency of the ingesta and at last the runs happens. 


\section{Infertility}

SARA may influence fertility of dairy cows in a roundabout way Besides calving and potentially the health of the infant calf (Enemark, 2008). Cycling feeding is an outcome of SARA which may diminish accessibility of energy and some other indispensable supplements to the cows and the infant by diminishing DMI during early lactation. This condition is related with fertility in cows during post-partum and deficient development of the ova (Britt, 1995).

\section{Economic loss}

SARA has extraordinary financial result to the dairy ventures everywhere throughout the world. The monetary lose due to SARA results from reduced milk production, poor proficiency of milk production, untimely automatic separating and increased passing loss (Krause and Oetzel, 2005). It was assessed to be US\$1.12/day per cow monetary loss in herds determined to have SARA (Stone, 1999). It was likewise revealed that, decreased feed consumption due to SARA came about impeded development in calves and evaluated in lost US\$10-13 for each animal alongside extra loss from liver sore happened in $15 \%$ of the cases.

\section{PREVENTIVE MEASURES}

\section{Physically effective fiber (peNDF)}

The peNDF identifies with the physical attributes of a feed which shows its capability to animate chewing (Mertens, 1997). Extended fodder particles in the feeding regimen contain adequate peNDF which advances chewing and salivary emission that support the acids coming about because of feed processing. In this manner, particle length of forages and the measure of forage fiber in the diet assume huge purpose on rumen $\mathrm{pH}$ through salivary buffering. Moreover, long forage fiber makes a skimming mat in the rumen, which animates reticulo-ruminal compressions to expel VFA by means of ingestion and section of liquid from rumen to bring down gut and in this manner decrease the danger of SARA.

Fibres are digested gradually than starch and sugar. In this way, incorporating peNDF in the diet hinders the rate of carbohydrate processing in the rumen. Reduced rate of carbohydrate absorption reduces the rate of VFA production, consequently, forestalls enormous drops in rumen $\mathrm{pH}$. Feeding long particle fiber can likewise move the site of starch processing from rumen to the lower gut, which incompletely reduces the hazard for ruminal acidosis (Yang and Beauchemin, 2006). It has, in this way, been suggested that, in any event $40 \%$ of the feed particles of dietary TMR for dairy cows ought to be longer than $8 \mathrm{~mm}$ in size.

The peNDF substance of the diet can be increased either by expanding NDF content or by expanding cleave length of forages (Beauchemin and Penner, 2009). Whichever way of expanding the peNDF substance of the diet at last builds chewing time and salivary discharge. The expanding peNDF substance of the diet by expanding the NDF content is generally more powerful as far as forestalling SARA than expanding forage particle length. In any case, more exploration is expected to more readily characterize the connections between dry matter intake, peNDF content and ruminal fermentability of diet.

\section{Preparation of diet}

Diets devoured by cows may contrast as often as possible from those that have been detailed because of mistakes in blending and feed sorting. It was accounted for that, cows favor littler feed particles than bigger ones (Leonardi and Armentano, 2003) which demonstrates that, regardless of whether the diet contains adequate peNDF, the bit that is really devoured may not. Some dairy ranchers add water to TMR to diminish dry matter substance so as to abstain from sorting. Adding water is intended to tie proportion particles together and make it hard to sorting against bigger forage particles. It was accounted for that, adding water to diminish a TMR dry matter from 80 to $64 \%$ decreased sorting for the littlest particles. Adding water to the rations can conceivably bring down dry matter intake in view of the filling impact of higher dampness proportions. Adding molasses to a dry TMR has been fairly appeared to forestall sorting by restricting activity (DeVries and Gill, 2012). Moreover, sorting can be limited by keeping away from over the top measures of long material in the TMR. It has been recommended that, additional roughage or straw ought not be longer than $2.5-5.0 \mathrm{~cm}$ (Shaver, 2002).

\section{Fermentability of feed}

The carbohydrate divisions inside diet contrast in their rate of absorption. Sugars and starches are digested quicker than fiber. Dietary starch is provided basically by grains and its rate of absorption in the rumen relies upon the sort of grain and how it is prepared. One way to deal with hinder the rate of fermentation is to supplant a bit of the grain with non-forage fiber sources, for example, beet mash, soybean structures, horse feed feast, distiller's grains, brewer's grains and corn gluten feed (Grant, 1997). Utilization of non-forage fiber sources decreases the measure of starch digested in the rumen. Besides, the best technique to decrease fermentation rate in the rumen is to expand the extent of forage in the diet. Adding forage to the diet not just builds chewing time and saliva emission, it additionally reduces VFA production round the day (Beauchemin et al., 2003). However, as the measure of forage increments in TMR, energy content declines proportionately. 


\section{Partitioning of carbohydrate}

It has been suggested that, for lactating dairy cows creating in excess of $30 \mathrm{~kg}$ of milk general rules for carbohydrate portion can be considered as $\mathrm{CF}=15-17 \%$, $\mathrm{ADF}=19-21 \%$, NDF (TMR) $=\mathbf{2 7 - 3 0 \% , ~ N D F ~ ( F o r a g e ) ~}=\mathbf{2 1 - 2 2} \%$, nonstructural carbohydrates, 35 to $40 \%$ and starch, 28 to $30 \%$, sugar $6 \%$ (Beauchemin and Penner, 2009). The ruminally degradable starch, NDF and carbohydrate ought to be 60 to $70 \%, 50$ to $60 \%$ and 50 to $55 \%$ of the absolute starch, NDF and carbohydrate substance of the diet. These rules should just be considered without bargaining energy prerequisites of the cows being referred to. Different rules in regards to physical structure and the proportions of auxiliary to nonstructural carbohydrate incorporate forage NDF to ruminally degradable starch $>1: 1$; NDF: nonstructural carbohydrates $>0.9$ and $<1.2$ and 15 to $20 \%$ eNDF with particle size $>3.8 \mathrm{~cm}$ long.

\section{Dietary protein}

Dietary protein levels have been accounted for to impact the occurrence of laminitis. Manson and Leaver (1988) contrasted diets and 16.1 versus $19.8 \%$ crude protein. The high protein diet fundamentally affected motion during clinical weakness for dairy cows somewhere in the range of 3 and 26 wk baby blues. It was considered the impact of 15.3 versus $18 \%$ dietary unrefined protein on solid calves and on those influenced with laminitis. It was seen that, high rates of ruminally degradable protein were answerable for faltering and laminitis. In any case, little data is accessible with respect to purpose of protein in the improvement of weakness. A few propositions include unfavorably susceptible histaminic responses to specific kinds of proteins (Nilsson, 1963) or a connection between high protein supplementation (Bazeley and Pinsent, 1984).

\section{Dietary yeast}

Utilization of microorganism to forestall neurotic changes in dairy cow is notable. Nocek et al. (2002a,b) announced that, inoculation of microorganisms into rumen was viable against SARA. Three kinds of lactate using microorganisms i.e., Enterococcus faeccium, Lactobacillus plantarum and Sacchoromyces cerevisae were applied intraruminaly. These microorganisms after immunization, viably forestalled collection of lactic acid and lead to high ruminal pH. However, direct immunization of Selenomonas ruminantium and Megasphaera elsdenii was sketchy since their endurance was short (Owens et al., 1998). In vitro examinations proposed that, Saccharomyces cerevisiae communicated with rumen microorganisms to diminish lactate collection. It infers that, yeast supplement might be helpful to the cows experiencing ruminal acidosis. In any case, Saccharomyces cerevisiae reduced the impact of a grain-put together ruminal acidosis challenge with respect to rumen fermentation. Conversely, Li et al. (2013) revealed that, assembly of short chain fatty acid settled ruminal $\mathrm{pH}$. Hereditary control of lactolytic microscopic organisms is a generally new thought with the point of expanding the lactate transformation limit and acid opposition of the microorganisms yet no industrially accessible item has yet been produced (Martin and Dean, 1989). Supplementation of dicarboxylic acids, for example, fumarate and maleate may likewise act along these lines however documentation is not yet accessible (Owens et al., 1998).

\section{Chewing activity}

The dairy cows normally burn through 2 to $6 \mathrm{~h} / \mathrm{d}$ for eating, 3 to $9 \mathrm{~h} / \mathrm{d}$ for ruminating and a limit of around $14 \mathrm{~h} / \mathrm{d}$ for chewing relying on the diet. Expanding peNDF of the diet either by expanding the NDF content or expanding the slash length of forages builds chewing time and thus salivary discharge. It was accounted for that, each extra kilogram of peNDF in a peNDF lacking diet can expand chewing time by up to 5-7 h/d contrasted with the diets containing satisfactory peNDF. In this manner, a little increment in peNDF substance of the diet can be successful when diets are low in fiber. Vegetable forages and high protein feeds have more buffering limit than grains (Jasaitis et al., 1987). Forages having little particles are less viable in invigorating rumination which brings about less saliva production. For instance, rate of salivation production for new grass, silage and grass feed was $0.94 \mathrm{ml}, 1.13 \mathrm{ml}$ and $3.25 \mathrm{ml} / \mathrm{g}$ individually (Bailey, 1958).

Although, expanding peNDF substance of diet builds chewing time, however the expansion in saliva yield because of increased chewing is not as incredible as expected since the increased progression of salivation during chewing is joined by a reduction in resting salivation discharge (Maekawa et al., 2002). It was accounted for that, the net increment altogether salivary emission because of $1 \mathrm{~h} / \mathrm{d}$ additionally chewing is around $7 \mathrm{~L}$ which may support just around $0.5 \mathrm{~kg}$ of ground grain. Consequently, the net impact of the steady saliva production on mean rumen $\mathrm{pH}$ is moderately little although an expansion in salivation emission during eating can help decrease the degree to which pH dips under 5.8 after suppers.

\section{Fermentation modifiers}

Feed added substances that help change the microbial environment of the rumen, for example, sodium bicarbonate, yeast, bacterial direct took care of microbials and monensin can help limit acidosis. Buffers might be added to most lactating cow's diet as a prudent step in avoidance of acidosis (Garry, 2002). They might be included situations where the fiber content in the feed is excessively low. It has been accounted for that, the expansion of $150 \mathrm{~g}$ of sodium bicarbonate to the lactation feed every day positively affected the milk yield (Downer and Cummings, 1985). Thus, a beneficial outcome has been shown on feed intake and milk fat rate. Sodium bicarbonate at 0.5 to $0.75 \%$ of DMI might be brought into the proportion progressively because of their low attractiveness. Buffers might be offered free decision to cattle 
dependent on the presumption that, ruminants will promptly expend the sum expected to reduce the impacts of SARA. Sodium bicarbonate can be given either blended into the ration or free choice. In any case, blending the bicarbonate into the ration was more compelling than giving it free decision.

\section{Adaptation}

Surface zone of ruminal papillae is influenced by diet (Xu and Allen, 1999). Offering high roughage diets during dry period may diminish papillae surface territory which reduces rate of VFA absorption (Allen et al., 2006). It was accounted for that, rumen papillae altogether increased in size and capacity to assimilate VFA was increased when animals were changed from roughage and straw based diet to a high energy diet containing a blend of grass feed and grain two wk preceding refreshing (Mertens, 1992). Dirksen et al. (1985) stressed the significance of versatile changes of the rumen mucosa for anticipation of acidosis. It was seen that, rumen papillae increased from $10 \mathrm{~mm} 2$ to $60 \mathrm{~mm} 2$ when cows were presented to high concentrate diets from four to six wks. Rumen papillae seemed to arrive at their most extreme length at 4 to 5 wk post-calving. In vivo VFA absorption rates performed at 14 wk post-calving were substantially more prominent around then contrasted and when cows were taken care of the feed straw diet. In another investigation, Stone et al. (2003) assessed papillae size and their capacity to retain valerate in 4 Holstein calves and watched substantial changeability in papillae size and ruminal ingestion of valerate.

Of the SCFAs, butyrate has been accounted for to be the most powerful trigger of epithelial expansion in colonic epithelial cells. Intra-ruminal mixture of butyrate has for some time been known to incite ruminal epithelial expansion in vivo. However, rather than in vivo investigations, butyrate has been appeared to evoke an inhibitory impact on ruminal epithelial multiplication in vitro. These differentiating results demonstrate that, butyrate alone can't advance epithelial expansion legitimately, rather acts through the arrival of certain hormones and development factors. It was accounted for that, EGF, IGF-1, GH, insulin and glucagon fixation increased in a portion subordinate way because of ruminal mixtures of blended SCFA which animated multiplication of ruminal epithelium for adjustment to the subsequent changes.

\section{Immunization}

There exist positive relationships between the counter Streptococcus bovis and hostile to Lactobacillus IgG in serum and salivation and pervasiveness of SARA (Shu et al., 1999). Contrasted with control group, guides in the vaccinated group had higher $(P<0.05)$ feed consumption, lower $(P<0.05)$ ruminal concentrations of lactate and lower quantities of Streptococcus bovis and Lactobacillus. So also, polyclonal antibodies arranged against S. bovis or Fusobacterium necrophorum when applied to calves, substantially decreased rumen concentrations of target microscopic organisms and increased $\mathrm{pH}$ in steers took care of high-grain diets (Calsamiglia et al., 2012). These investigations recommend that, the danger of lactic acidosis can be decreased by inoculation against S. bovis and Lactobacillus (Gill et al., 2000). In another examination, the danger of lactic acidosis in sheep was reduced by inoculation with a live Streptococcus bovis antibody (Shu et al., 1999).

\section{Bunk management}

Congestion, rivalry for bunk space, constrained access to feed, rare TMR push-up in the bunk, segment feeding, stall comfort and long milking parlor time increment the danger of SARA (Stone, 2004). In this way, the components of the stall must be sufficient for the size of animal that is being housed, particularly stall length, width and jump space. Moreover, satisfactory stall space ought to be given to permit ruminating to roughly 12 to $14 \mathrm{~h} / \mathrm{d}$. Ideal materials ought to be given for cow comfort.

\section{CONCLUSION}

Sub-acute ruminal acidosis (SARA) is a multi-factorial silent threat for financial issue, animal health and welfare even in well managed dairy herds. As efficiency builds up, the interest for quickly fermentable carbohydrate increments proportionately which makes high yielding cows increasingly prone to SARA. Along these lines, planning high energy diet with satisfactory peNDF is a reliable predictor under traditional feeding framework. Moreover, subclinical course of the disease with complex etiology and pathogenesis confound its outline, analysis, monitoring and avoidance. Cautiously adjusting rumen to changes in diet, reducing fermentability of carbohydrate part, providing adequate peNDF to keep up ideal digesta pool that invigorate satisfactory salivary buffer course through rumination and elevate ruminal motility to expand VFA absorption are the fundamental variables to be considered in controlling SARA.

\section{DECLARATIONS}

Corresponding Author

E-mail: emran@cvasu.ac.bd

Authors' Contribution

I am the sole contributor of the manuscript. 


\section{Conflict of interests}

None.

Acknowledgements

The author acknowledges Department of Animal Science and Nutrition, Chattogram Veterinary and Animal Sciences University.

\section{REFERENCES}

Allen MS (2000). Effects of diet on short-term regulation of feed intake by lactating dairy cattle. Journal of Dairy Science, 83 (7):15981624. https://doi:10.3168/jds.S0022-0302(00)75030-2

Allen MS, Voelker JA, Oba M. Physically effective fiber and regulation of ruminal pH: More than just chewing. Production Diseases in Farm Animals. NP Joshi and TH Herdt, ed. Wageningen Academic Publishers, Wageningen, the Netherlands. 270-8. Google Scholar

Andersen PH (2003). Bovine endotoxicosis - Some aspects of relevance to production diseases. A review. Acta Veterinaria Scandinavica, Supplement, 44 (98):141-155. https://doi:10.1186/1751-0147-44-s1-s141

Ash RW (1959). Inhibition and excitation of reticulo-rumen contractions following the introduction of acids into the rumen and abomasum. The Journal of Physiology, 147 (1): 58-73. https://doi:10.1113/ jphysiol.1959.sp006221

Bailey CB (1958). Nutritional Ecology of the Ruminant. $2^{\text {nd }}$ edn. Cornell University Press. Google Scholar

Bauman DE and Griinari JM (2001). Regulation and nutritional manipulation of milk fat: Low-fat milk syndrome. Livestock Production Science, 70 (1-2):15-29. https://doi.org/10.1016/S0301-6226(01)00195-6 I Google Scholar

Bauman DE, Baumgard LH, Corl BA and GriinaridJM (1999). Biosynthesis of conjugated linoleic acid in ruminants, pp. 1-14. Google Scholar

Bauman DE, Baumgard LH, Corl BA, Griinari DJ. Biosynthesis of conjugated linoleic acid in ruminants. Proceedings - American Society of Animal Science, 77: 1-14. Google Scholar

Bauman DE, Harvatine KJ and Lock AL (2011). Nutrigenomics, Rumen-Derived Bioactive Fatty Acids and the Regulation of Milk Fat Synthesis. Annual Review of Nutrition, 31 (1):299-319. https://doi:10.1146/ annurev.nutr.012809.104648

Baumgard LH, Corl BA, Dwyer DA, Saebø and Bauman DE (2000). Identification of the conjugated linoleic acid isomer that inhibits milk fat synthesis. American Journal of Physiology - Regulatory Integrative and Comparative Physiology, 278 (1 47-1):R179-R184. https://doi:10.1152/ajpregu.2000.278.1.r179

Bazeley K and Pinsent PJ (1984). Preliminary observations on a series of outbreaks of acute laminitis in dairy cattle. The Veterinary Record, 115 (24):619-622. https://doi:10.1136/vr.115.24.619

Beauchemin K and Penner G (2009). New developments in understanding ruminal acidosis in dairy cows. InTri-State dairy nutrition conference. pp 1-12. Google Scholar

Beauchemin KA, Yang WZ, Morgavi DP, Ghorbani GR, Kautz W and Leedle JAZ (2003). Effects of bacterial direct-fed microbials and yeast on site and extent of digestion, blood chemistry, and subclinical ruminal acidosis in feedlot cattle. Journal of Animal Science, 81 (6):1628-1640. https://doi:10.2527/2003.8161628x

Boosman R, Németh F and Gruys E (1991). Bovine laminitis: clinical aspects, pathology and pathogenesis with reference to acute equine laminitis. The Veterinary quarterly, 13 (3):163-171. https://doi:10.1080/01652176.1991.9694302

Brent BE (1976). Relationship of acidosis to other feedlot ailments. Journal of animal science, 43 (4):930-935. https://doi:10.2527/jas1976.434930x

Britt JH (1995). Relationships between postpartum nutrition, weight loss and fertility. Cattle Practice, 3:79-83. Google Scholar

Britton RA and Stock RA (1987). Acidosis, rate of starch digestion and intake. Annual report-Oklahoma Agricultural Experiment Station. Proceedings of the 1986 Feed Intake Symposium: 125-137. Google Scholar

Calsamiglia S, Blanch M, Ferret A and Moya D (2012). Is subacute ruminal acidosis a pH related problem? Causes and tools for its control. Animal Feed Science and Technology, 172 (1-2):42-50. https://doi:10.1016/j.anifeedsci.2011.12.007

Chavance J (1946). Histamine theory and treatment of laminitis. Veterinary medicine, 41:199-201. PMID: 21028740 I Google Scholar

Cheng KJ, McAllister TA, Popp JD, Hristov AN, Mir Z and Shin HT (1998). A Review of Bloat in Feedlot Cattle. Journal of Animal Science, 76 (1):299-308. https://doi:10.2527/1998.761299x

Coon RE, Duffield TF and DeVries TJ (2019). Short communication: Risk of subacute ruminal acidosis affects the feed sorting behavior and milk production of early lactation cows. Journal of Dairy Science, 102 (1):652-659. https://doi:10.3168/jds.2018-15064

De Veth MJ and Kolver ES (2001). Diurnal variation in pH reduces digestion and synthesis of microbial protein when pasture is fermented in continuous culture. Journal of Dairy Science, 84 (9):2066-2072. https://doi:10.3168/jds.S0022-0302(01)74651-6

DeVries TJ and Gill RM (2012). Adding liquid feed to a total mixed ration reduces feed sorting behavior and improves productivity of lactating dairy cows. Journal of Dairy Science, 95 (5):2648-2655. https://doi:10.3168/jds.2011-4965

Dirksen G, Liebich HG, Brosi G, Hagemeister H and Mayer E (1984). Morphology of the rumen mucosa and fatty acid absorption in cattleimportant factors for health and production. Zentralblatt fur Veterinarmedizin Reihe A, 31 (6):414-41430. PMID: 6435341 I Google Scholar

Dirksen GU, Liebich HG and Mayer E (1985). Adaptive changes of the ruminal mucosa and their functional and clinical significance. Bovine Practitioner, 20:116-120. Google Scholar

Downer JV and Cummings KR (1985). A ten year review of lactation study. Journal of Dairy Science, 68 (Suppl. 1):191-201. Google Scholar

Enemark J, Jorgensen RJ and Enemark P (2002). Rumen acidosis with special emphasis on diagnostic aspects of subclinical rumen acidosis: a review. Veterinarija ir zootechnika, 20 (42):16-29. Google Scholar

Enemark JMD (2008). The monitoring, prevention and treatment of sub-acute ruminal acidosis (SARA): A review. Veterinary Journal, 176 (1):32-43. https://doi:10.1016/j.tvjl.2007.12.021

Fairfield AM, Plaizier JC, Duffield TF, Lindinger MI, Bagg R, Dick P and McBride BW (2007). Effects of prepartum administration of a monensin controlled release capsule on rumen $\mathrm{pH}$, feed intake, and milk production of transition dairy cows. Journal of Dairy Science, 90 (2):937-945. https://doi:10.3168/jds.S0022-0302(07)71577-1

Garry FB (2002). Indigestion in Ruminants. Large animal internal medicine, 3:722-747. Google Scholar

Giesy JG, Viswanadha S, Hanson TW, Falen LR, McGuire MA, Skaric CH and Vinci A (1999). Effects of calcium salts of conjugated linoleic acid (CLA) on estimated energy balance in Holstein cows early in lactation. Journal of Dairy Science (Supplement), 1 (1):74-74. Google Scholar 
Gill HS, Shu Q and Leng RA (2000). Immunization with Streptococcus bovis protects against lactic acidosis in sheep. Vaccine, 18 (23):2541-2548. https://doi:10.1016/S0264-410X(00)00017-7

Goad DW, Goad CL and Nagaraja TG (1998). Ruminal Microbial and Fermentative Changes Associated with Experimentally Induced Subacute Acidosis in Steers. Journal of Animal Science, 76 (1):234-241. https://doi:10.2527/1998.761234x

Gozho GN, Krause DO and Plaizier JC (2007). Ruminal lipopolysaccharide concentration and inflammatory response during grain-induced subacuteruminai acidosis in dairy cows. Journal of Dairy Science, 90 (2):856-866. https://doi:10.3168/jds.S0022-0302(07)71569-2

Grant RJ (1997). Interactions among Forages and Nonforage Fiber Sources. Journal of Dairy Science, 80 (7):1438-1446. https://doi:10.3168/jds.S0022-0302(97)76073-9

Griinari JM and Bauman DE (1999). Biosynthesis of conjugated linoleic acid and its incorporation into meat and milk in ruminants. Advances in conjugated linoleic acid research, 1 (1):180-200. Google Scholar

Hoover WH (1986). Chemical Factors Involved in Ruminal Fiber Digestion. Journal of Dairy Science, 69 (10):2755-2766 https://doi:10.3168/jds.S0022-0302(86)80724-X

Hu W, Murphy MR, Constable PD and Block E (2007). Dietary cation-anion difference effects on performance and acid-base status of dairy cows postpartum. Journal of Dairy Science, 90 (7):3367-3375. https://doi:10.3168/jds.2006-515

Hunt RJ, Allen D and Moore JN (1990). Effect of endotoxin administration on equine digital hemodynamics and starling forces. American journal of veterinary research, 51 (11):1703-1707. PMID: 2240793 I Google Scholar

Ip C, Banni S, Angioni E, Carta G, McGinley J, Thompson HJ, Barbano D and Bauman D (1999). Conjugated Linoleic Acid-Enriched Butter Fat Alters Mammary Gland Morphogenesis and Reduces Cancer Risk in Rats. The Journal of Nutrition, 129 (12):2135-2142. https://doi:10.1093/in/129.12.2135

Jasaitis DK, Wohlt JE and Evans JL (1987). Influence of Feed Ion Content on Buffering Capacity of Ruminant Feedstuffs In vitro. Journal of Dairy Science, 70 (7):1391-1403. https://doi:10.3168/jds.S0022-0302(87)80161-3

Jing L, Dewanckele L, Vlaeminck B, Van Straalen WM, Koopmans A and Fievez V (2018). Susceptibility of dairy cows to subacute ruminal acidosis is reflected in milk fatty acid proportions, with C18:1 trans-10 as primary and C15:0 and C18:1 trans-11 as secondary indicators. Journal of Dairy Science, 101 (11):9827-9840. https://doi:10.3168/jds.2018-14903

Khafipoor E, Krause DO, Plaizier JC. (2007). Induction of subacute ruminal acidosis (SARA) by replacing alfalfa hay with alfalfa pellets does not stimulate inflammatory response in lactating dairy cows. Journal of Animal Science, 90:654-654. Google Scholar

Khalouei H, Alamouti AA, Mohammadi-Sangcheshmeh A, Farzaneh N, Plaizier JC and Khafipour E (2016). 0146 Subacute ruminal acidosis negatively affects conception rate in Holstein heifers. Journal of Animal Science, 94 (suppl_5):69-69. https://doi:10.2527/jam20160146

Kleen JL, Hooijer GA, Rehage J and Noordhuizen JPTM (2003). Subacute ruminal acidosis (SARA): A review. Journal of Veterinary Medicine Series A: Physiology Pathology Clinical Medicine, 50 (8):406-414. https://doi:10.1046/j.1439-0442.2003.00569.x

Krajcarski-Hunt H, Plaizier JC, Walton JP, Spratt R and McBride BW (2002). Short communication: Effect of subacute ruminal acidosis on in situ fiber digestion in lactating dairy cows. Journal of Dairy Science, 85(3):570-573. https://doi:10.3168/jds.S00220302(02)74110-6

Krause KM and Combs DK (2003). Effects of forage particle size, forage source, and grain fermentability on performance and ruminal pH in midlactation cows. Journal of Dairy Science, 86 (4):1382-1397. https://doi:10.3168/jds.S0022-0302(03)73722-9

Krause KM and Oetzel GR (2006). Understanding and preventing subacute ruminal acidosis in dairy herds: A review. Animal Feed Science and Technology, 126 (3-4):215-236. https://doi:10.1016/j.anifeedsci.2005.08.004

Krehbiel CR, Britton RA, Harmon DL, Wester TJ and Stock RA (1995). The effects of ruminal acidosis on volatile fatty acid absorption and plasma activities of pancreatic enzymes in lambs. Journal of animal science, 73 (10):3111-3121. https://doi:10.2527/1995.73103111x

Leonardi C and Armentano LE (2003). Effect of quantity, quality, and length of alfalfa hay on selective consumption by dairy cows. Journal of Dairy Science, 86 (2):557-564. https://doi:10.3168/jds.S0022-0302(03)73634-0

Li S, Khafipour E, Yoon I and Scott M and Plaizier J (2013). Saccharomyces cerevisiae fermentation product stabilized rumen microbial communities of lactating dairy cows during subacute ruminal acidosis. In, Congress on Gastrointestinal Function Meeting, Chicago, IL. Google Scholar

Maekawa M, Beauchemin KA and Christensen DA (2002). Effect of concentrate level and feeding management on chewing activities, saliva production, and ruminal $\mathrm{pH}$ of lactating dairy cows. Journal of Dairy Science, $85(5): 1165-1175$. https://doi:10.3168/jds.S0022-0302(02)74179-9

Martin SA and Dean GF (1989) Use of genetically engineered rumen bacteria may aid in prevention of acidosis in cattle. Feedstuffs, 1989:17-18,38. Google Scholar

Mertens DR (1992). Nonstructural and structural carbohydrates. Large dairy herd management, 1:219-235. Google Scholar

Mertens DR (1997). Creating a System for Meeting the Fiber Requirements of Dairy Cows. Journal of Dairy Science, 80 (7):1463-1481. https://doi:10.3168/jds.S0022-0302(97)76075-2

Nilsson SA (1963). Clinical, morphological, and experimental studies of laminitis in cattle. ActaVeterinariaScandinavica, 4 (Suppl. 1):304, pp. 304. Google Scholar

Nocek JE (1997). Bovine Acidosis: Implications on Laminitis. Journal of Dairy Science, 80 (5):1005-1028. https://doi:10.3168/jds.S00220302(97)76026-0

Nocek JE, Allman JG and Kautz WP (2002a). Evaluation of an indwelling ruminal probe methodology and effect of grain level on diurnal pH variation in dairy cattle. Journal of Dairy Science, 85 (2):422-428. https://doi:10.3168/jds.S0022-0302(02)74090-3

Nocek JE, Kautz WP, Leedle JAZ and Allman JG (2002b). Ruminal supplementation of direct-fed microbials on diurnal pH variation and in situ digestion in dairy cattle. Journal of Dairy Science, 85 (2):429-433. https://doi:10.3168/jds.S0022-0302(02)74091-5

Nordlund KV, Garrett EF and Oetzel GR (1995). Herd-based rumenocentesis: a clinical approach to the diagnosis of subacute rumen acidosis. Food Animal Medicine and Management, 17 (8):s48-s48. Link I Google Scholar

Oetzel GR (2015). Subacute Ruminal Acidosis in Dairy Herds: Physiology, Pathophysiology, Milk Fat Responses, and Nutritional Management. pp 89-119. Google Scholar

Owens FN, Secrist DS, Hill WJ and Gill DR (1998). Acidosis in Cattle: A Review. Journal of Animal Science, 76 (1):275-286. https://doi:10.2527/1998.761275x

Palmquist DL, Denise Beaulieu A and Barbano DM (1993). Feed and Animal Factors Influencing Milk Fat Composition. Journal of Dairy Science, 76 (6):1753-1771. https://doi:10.3168/jds.S0022-0302(93)77508-6

Parodi PW (1977). Conjugated Octadecadienoic Acids of Milk Fat. Journal of Dairy Science, 60 (10):1550-1553. https://doi:10.3168/jds.S0022-0302(77)84068-X

Penner GB, Steele MA, Aschenbach JR and McBride BW (2011). Ruminant nutrition symposium: Molecular adaptation of ruminal epithelia to highly fermentable diets. Journal of Animal Science, 89 (4):1108-1119. https://doi:10.2527/jas.2010-3378 
Plaizier JC, Krause DO, Gozho GN and McBride BW (2008). Subacute ruminal acidosis in dairy cows: The physiological causes, incidence and consequences. Veterinary Journal, 176 (1):21-31. https://doi:10.1016/j.tvjl.2007.12.016

Plaizier JC, Li S, Danscher AM, Derakshani H, Andersen PH and Khafipour E (2017). Changes in Microbiota in Rumen Digesta and Feces Due to a Grain-Based Subacute Ruminal Acidosis (SARA) Challenge. Microbial Ecology, 74 (2):485-495. https://doi:10.1007/s00248-017-0940-z

Russell JB and Allen MS (1984). Physiological basis for interactions among rumen bacteria using Streptococcus bovis and Megasphaeraelsdenii as a model. American Society for Microbiology, pp. 239-247. Google Scholar

Russell JB and Rychlik JL (2001). Factors that alter rumen microbial ecology. Science, 292 (5519):1119-1122. https://doi:10.1126/science.1058830

Russell JB and Wilson DB (1996). Why Are Ruminal Cellulolytic Bacteria Unable to Digest Cellulose at Low pH? Journal of Dairy Science, 79 (8):1503-1509. https://doi:10.3168/jds.S0022-0302(96)76510-4

Sarashina T, Ichijo S, Takahashi J and Osame S (1990). Origin of abomasum gas in the cows with displaced abomasum. Nippon juigakuzasshi The Japanese journal of veterinary science, 52 (2):371-378. https://doi:10.1292/jvms1939.52.371

Shaver R (2002). Rumen acidosis in dairy cattle: Bunk management considerations. Advanced Dairy Technology, 14 (Dm):241-249. Google Scholar

Shaver RD (1997). Nutritional Risk Factors in the Etiology of Left Displaced Abomasum in Dairy Cows: A Review. Journal of Dairy Science, 80 (10):2449-2453. https://doi:10.3168/jds.S0022-0302 (97)76197-6

Shinozaki K (1959). Studies on experimental bloat in ruminants 5 . Effects of various volatile fatty acids introduced into the rumen on the rumen motility. Tohoku Journal of Agricultural Research, 9 (4):237-250. Google Scholar

Shu Q, Gill HS, Hennessy DW, Leng RA, Bird SH and Rowe JB (1999). Immunisation against lactic acidosis in cattle. Research in Veterinary Science, 67 (1):65-71. https://doi:10.1053/rvsc.1998.0284

Stone WC (1999). The effect of subclinical rumen acidosis on milk components. In, Proceedings Cornell nutrition conference for feed manufacturers. Link I Google Scholar

Stone WC (2004). Nutritional approaches to minimize subacute ruminal acidosis and laminitis in dairy cattle. Journal of Dairy Science, 87 (SUPPL. 1). https://doi:10.3168/jds.S0022-0302(04)70057-0

Stone WC, Bulkley SL, Aneshansley DJ and Alcaraz AL (2003). An evaluation of rumen papillae in Holstein heifers during the transition period. Journal of Dairy Science, 86 (Suppl 1):227-227. Google Scholar

Thomas PC and Martin PA (1988). The Influence of Nutrient Balance on Milk Yield and Composition. Nutrition and Lactation in the Dairy Cow, pp. 97-118. https://doi:10.1016/b978-0-408-00717-7.50011-3

Vargas-Bello-Pérez E and Garnsworthy PC (2013). Trans fatty acids and their role in the milk dairy cows. International Journal of Agriculture and Natural Resources, 40(3): 449-473. Google Scholar

Wiese BI, Campbell J, Hendrick S and Penner GB (2017). Ruminal pH, short-chain fatty acid concentrations, and serum acute phase protein concentrations during finishing for steers with and without rumen and liver pathology. Canadian Journal of Animal Science, 97 (4):581-589. https://doi.org/10.1139/cjas-2016-0212

$\mathrm{Xu} \mathrm{J}$ and Allen MS (1999). Effects of dietary lactose compared with ground corn grain on the growth rate of ruminal papillae and rate of valerate absorption from the rumen. South African Journal of Animal Science, 29. Google Scholar

Yang WZ and Beauchemin KA (2006). Physically effective fiber: Method of determination and effects on chewing, ruminal acidosis, and digestion by dairy cows. Journal of dairy science, 89(7): 2618-2633. https://doi.org/10.3168/jds.S0022-0302(06)72339-6 I Google $\underline{\text { Scholar }}$ 